\title{
Study on lifestyle-intervention and impaired glucose tolerance Maastricht (SLIM): design and screening results
}

Citation for published version (APA):

Mensink, M. R., Corpeleijn, E., Feskens, E., Kruijshoop, M., Saris, W. H. M., de Bruin, T. W. A., \& Blaak, E. E. (2003). Study on lifestyle-intervention and impaired glucose tolerance Maastricht (SLIM): design and screening results. Diabetes Research and Clinical Practice, 61(1), 49-58. https://doi.org/10.1016/S01688227(03)00067-6

Document status and date:

Published: 01/01/2003

DOI:

10.1016/S0168-8227(03)00067-6

Document Version:

Publisher's PDF, also known as Version of record

Please check the document version of this publication:

- A submitted manuscript is the version of the article upon submission and before peer-review. There can be important differences between the submitted version and the official published version of record.

People interested in the research are advised to contact the author for the final version of the publication, or visit the DOI to the publisher's website.

- The final author version and the galley proof are versions of the publication after peer review.

- The final published version features the final layout of the paper including the volume, issue and page numbers.

Link to publication

\footnotetext{
General rights rights.

- You may freely distribute the URL identifying the publication in the public portal. please follow below link for the End User Agreement:

www.umlib.nl/taverne-license

Take down policy

If you believe that this document breaches copyright please contact us at:

repository@maastrichtuniversity.nl

providing details and we will investigate your claim.
}

Copyright and moral rights for the publications made accessible in the public portal are retained by the authors and/or other copyright owners and it is a condition of accessing publications that users recognise and abide by the legal requirements associated with these

- Users may download and print one copy of any publication from the public portal for the purpose of private study or research.

- You may not further distribute the material or use it for any profit-making activity or commercial gain

If the publication is distributed under the terms of Article 25fa of the Dutch Copyright Act, indicated by the "Taverne" license above, 


\title{
Study on lifestyle-intervention and impaired glucose tolerance Maastricht (SLIM): design and screening results
}

\author{
Marco Mensink ${ }^{\mathrm{a}, *}$, Eva Corpeleijn ${ }^{\mathrm{a}}$, Edith J.M. Feskens ${ }^{\mathrm{b}}$, \\ Margriet Kruijshoop ${ }^{c}$, Wim H.M. Saris ${ }^{a}$, Tjerk W.A. de Bruin ${ }^{c}$, \\ Ellen E. Blaak ${ }^{\text {a }}$ \\ ${ }^{a}$ Department of Human Biology, Nutrition and Toxicology Research Institute Maastricht (NUTRIM), Maastricht University, \\ P.O. Box 616, 6200 MD Maastricht, Netherlands \\ ${ }^{\mathrm{b}}$ Department of Health and Nutrition, National Institute for Public Health and the Environment, Bilthoven, Netherlands \\ ${ }^{\mathrm{c}}$ Department of Medicine and Endocrinology, Cardiovascular Research Institute Maastricht, (CARIM), University Hospital Maastricht, \\ Maastricht, Netherlands
}

Received 11 December 2002; received in revised form 25 February 2003; accepted 10 March 2003

\begin{abstract}
The study on lifestyle-intervention and impaired glucose tolerance Maastricht (SLIM) is a 3 years randomised clinical trial designed to evaluate the effect of a combined diet and physical activity intervention program on glucose tolerance in a Dutch population at increased risk for developing type 2 diabetes. Here the design of the lifestyle-intervention study is described and results are presented from the preliminary population screening, conducted between March 1999 and June 2000. In total, 2820 subjects with an increased risk of having disturbances in glucose homeostasis (i.e. age $>40$ years and BMI $>25 \mathrm{~kg} / \mathrm{m}^{2}$ or a family history of diabetes) underwent a first oral glucose tolerance test (OGTT). Abnormal glucose homeostasis was detected in 826 subjects (30.4\%): 226 type 2 diabetes (type 2DM, 8.3\%), 215 impaired fasting glucose (IFG, 7.9\%) and 385 impaired glucose tolerance (IGT, 14.2\%). Both increasing age and BMI were strongly related to the prevalence of IGT and diabetes. After a second OGTT, 114 subjects with glucose intolerance and in otherwise good health were eligible for participation in the intervention study (SLIM). The high prevalence of disturbances in glucose homeostasis observed in the preliminary screening underscore the importance of early (lifestyle) interventions in those at risk for developing diabetes. SLIM will address this topic in the Dutch population.
\end{abstract}

(C) 2003 Elsevier Science Ireland Ltd. All rights reserved.

Keywords: Lifestyle intervention; Prevalence; Impaired glucose tolerance; Type 2 diabetes; Population screening

\section{Introduction}

* Corresponding author. Tel.: +31-43-388-4258; fax: +3143-367-0976.

E-mail address: m.mensink@hb.unimaas.nl (M. Mensink).
Type 2 diabetes mellitus is rapidly becoming one of the main health issues in the 21 st century. Prevalence has increased explosively in the last two 
decades, and global estimates indicate a further rise from a current 150 million people with diabetes, to 300 million in 2025 [1,2]. Impaired glucose tolerance (IGT) is the obligatory transition state preceding type 2 diabetes. Prevalence of IGT varies widely between populations, from as low as $2.0 \%$ in rural populations to more than $20 \%$ in high-risk populations [3]. The cumulative incidence of type 2 diabetes in subjects with IGT ranged from 3.6 to $8.7 \%$ per year in six prospective studies [4], and is strongly related to the fasting and the 2-h plasma glucose concentrations at the time of IGT recognition [4,5]. The most important modifiable risk factor for progression from IGT to diabetes is obesity. Body mass index (BMI) at the time of IGT recognition is a strong predictor of progression, independently of fasting and 2-h blood glucose concentrations [4]. Dietary factors, especially a high fat intake, are also related to the risk of conversion from IGT to diabetes [6].

Several recent studies have reported the feasibility and efficacy of interventions to prevent or delay the progression to type 2 diabetes in subjects with IGT [7-13]. Acarbose, [13], as well as metformin [12], have been shown to reduce the incidence of diabetes in a population with IGT. Other studies have focused on the potential of lifestyle changes to reduce the progression rate from IGT to type 2 diabetes. The Finnish diabetes prevention study (DPS) [11] and the US diabetes prevention program (DPP) [12] reported that weight-loss, changes in dietary intake, and increased physical activity resulted in a 58\% reduction in the incidence of diabetes after a mean follow-up of only 3 years. Moreover, lifestyleintervention was much more effective in reducing the incidence of diabetes than pharmacological intervention (i.e. metformin) [12]. It is important to confirm these observations in different populations, with a different dietary and physical activity background, and a different attitude towards changing lifestyle-habits.

The study on lifestyle-intervention and impaired glucose tolerance Maastricht (SLIM) is a 3 years randomised clinical trial designed to evaluate the effect of a combined diet and physical activity intervention program on glucose tolerance in a Dutch population at increased risk for developing type 2 diabetes. Furthermore, we will consider changes in anthropometric measurements, aerobic capacity and cardiovascular risk factors. Additional measurements will be performed in subgroups of the study population in a search for underlying mechanisms.

The objective of this report is to describe the design of the lifestyle-intervention study and to evaluate the results of the preliminary population screening, from which the subjects were recruited for the intervention study. Data are presented about the prevalence of disturbances in glucose homeostasis in a middle-aged Dutch population.

\section{Study design and methods}

SLIM is designed to study whether a diet/ physical activity intervention program can improve glucose tolerance in subjects with a high risk for developing type 2 diabetes mellitus. The total duration of the study is 3 years. The medical ethical review committee of Maastricht University approved the study protocol, and all subjects gave their written informed consent before the start of the study.

\subsection{Recruitment of subjects}

The recruitment period started in March 1999 and was completed at the end of May 2000.

\subsubsection{Preliminary screening}

Subjects with an increased risk for glucose intolerance, i.e. those of age $>40$ years and a family history of diabetes or a BMI $>25 \mathrm{~kg} / \mathrm{m}^{2}$, were selected from a large existing cohort, monitoring health and disease in the general population [14], and invited to undergo a standard oral glucose tolerance test (OGTT) (glucose load 75 g) [15]. Blood glucose was measured in capillary blood using the Glucometer Elite (Bayer, Zurich, Schweiz). Furthermore, body weight was measured, without wearing shoes and jackets. Subjects with known diabetes, or those with fasting glucose values $>8.5 \mathrm{mmol} / \mathrm{l}$ did not participate in the OGTT. 


\subsubsection{Second OGTT}

Those subjects with a 2-h blood glucose concentration $>7.8 \mathrm{mmol} / \mathrm{l}$ at the preliminary screening and which were otherwise in good health (i.e. no history of cardiovascular disease, or any (chronic) disease or medication use that makes participation in a lifestyle intervention program impossible) were invited for a second OGTT. During this second OGTT, glucose tolerance was measured in venous plasma. Furthermore a medical history was taken, a physical examination was performed and several additional measurements were performed (see Section 2.3, below).

\subsubsection{Final recruitment}

For definitive inclusion in the lifestyle-intervention study, mean 2-h glucose concentration of both OGTTs had to be between 7.8 and $12.5 \mathrm{mmol} / 1$, together with a fasting glucose concentration of less than $7.8 \mathrm{mmol} / 1$. Other inclusion and exclusion criteria for participation in the intervention study are indicated in Table 1. To follow changes in glucose tolerance over time, data obtained by the second (venous) OGTT were used as baseline values.

After final recruitment, subjects were randomised to two study groups, the lifestyle intervention group or the control group. Randomisation was carried out with stratification for sex and mean 2 h-plasma glucose concentration.

Table 1

Inclusion and exclusion criteria for the lifestyle-intervention study (SLIM)

\begin{tabular}{|c|c|}
\hline \multirow{4}{*}{$\begin{array}{l}\text { Inclusion } \\
\text { criteria }\end{array}$} & Mean 2-h blood glucose $\geq 7.8$ and $\leq 12.5 \mathrm{mmol} / 1$ \\
\hline & Mean fasting blood glucose $\leq 7.8 \mathrm{mmol} / \mathrm{l}$ \\
\hline & Caucasian \\
\hline & Age $40-70$ years \\
\hline Exclusion & Known diabetes mellitus \\
\hline & $\begin{array}{l}\text { Mean 2-h blood glucose }>12.5 \mathrm{mmol} / \mathrm{lMean} \\
\text { fasting blood glucose }>7.8 \mathrm{mmol} / \mathrm{l}\end{array}$ \\
\hline & $\begin{array}{l}\text { Any chronic illness that makes } 5 \text {-years survival } \\
\text { improbable, or that interferes with glucose }\end{array}$ \\
\hline & tolerance, or that makes participation in a \\
\hline & lifestyle-intervention impossible \\
\hline & $\begin{array}{l}\text { Medication known to interfere with glucose } \\
\text { tolerance }\end{array}$ \\
\hline & $\begin{array}{l}\text { Participation in a regular vigorous exercise } \\
\text { and/or diet program }\end{array}$ \\
\hline
\end{tabular}

Based on the preliminary results after 1 year of the Finnish DPS [16], we calculated that 50-60 subjects per group would be sufficient to detect a $1.0 \mathrm{mmol} / \mathrm{l}$ difference in the 2-h glucose concentration between groups.

\subsection{Lifestyle-intervention program}

The intervention program consists of a dietary and physical activity part.

\subsubsection{Dietary intervention}

Dietary recommendations are based on the Dutch guidelines for a healthy diet (Dutch Nutrition Council, 1992, see Table 2). Participants are encouraged to stop smoking and, if necessary, to reduce alcohol intake. Dietary advice is given at regular intervals by a skilled dietician on an individual basis after consideration of a 3 days food record (see Table 2). A body weight loss of $5-7 \%$ is the objective. If subjects do not loose weight on this regimen during the first year, mild energy restriction is prescribed during the second year. No very-low calorie diet or dietary products are used to encourage weight loss.

\subsubsection{Exercise intervention}

Subjects are encouraged to increase their level of physical activity to at least $30 \mathrm{~min}$ of moderate physical activity a day for at least 5 days a week [17]. Individual advice is given on how to increase daily physical activity (walking, cycling, swimming), and goals are set. Furthermore, subjects are encouraged to participate in an exercise program, especially designed for this study, including components of aerobic exercise training and components of resistance training [18]. Subjects have free access to these training sessions, and are stimulated to participate for at least $1 \mathrm{~h} \mathrm{a}$ week. Participation in the exercise sessions is recorded.

\subsubsection{Control group}

Subjects in the control group are given, oral and written information, about the beneficial effects of a healthy diet, weight loss and increased physical activity, whereas no individual advice or programs are provided. No additional appointments are 
Table 2

Details of the dietary intervention

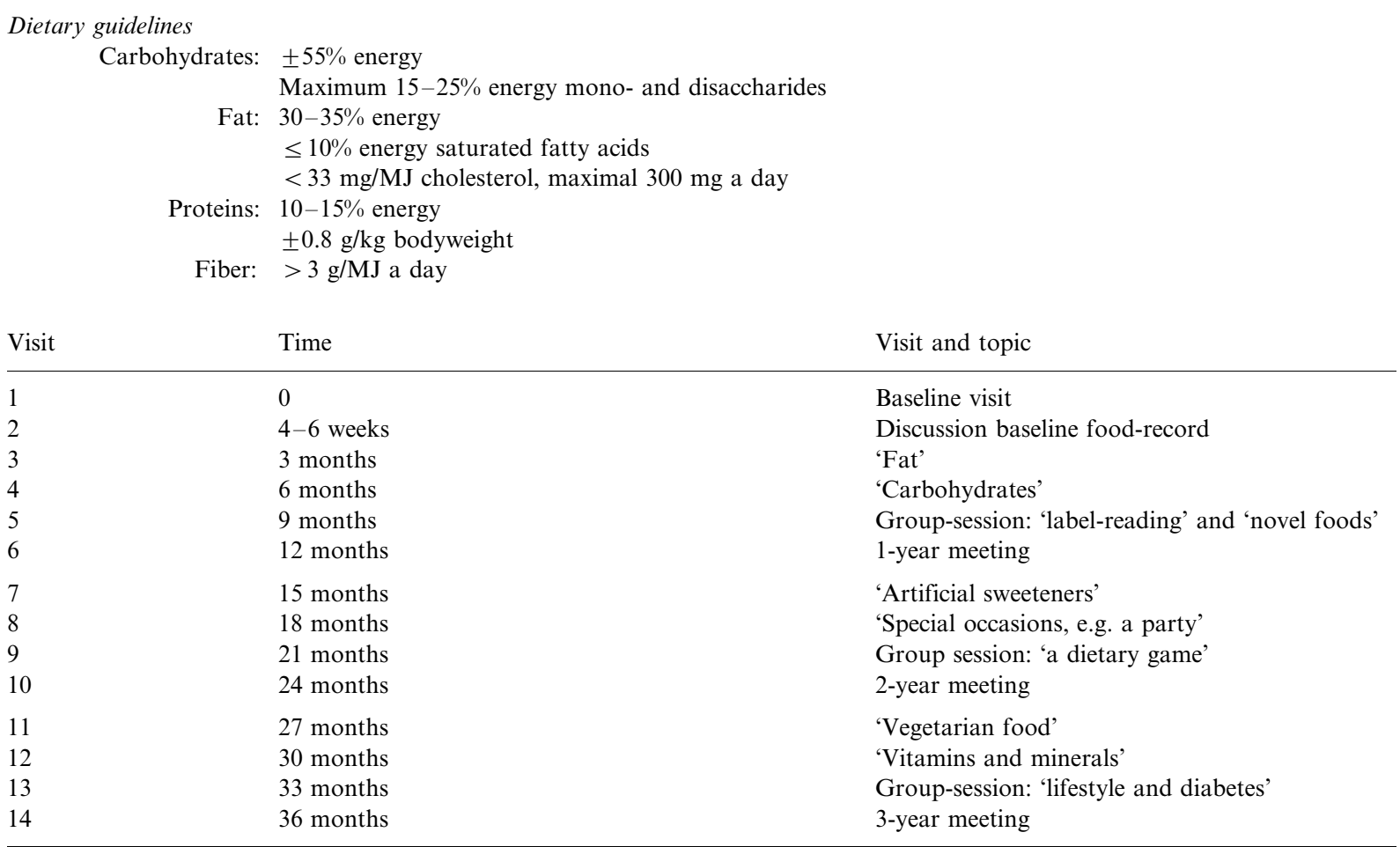

scheduled, apart from the annual visits for followup measurements.

\subsection{Measurements}

At the start of the study, and every year thereafter several measurements are performed, in both the intervention and control group.

\subsubsection{Laboratory assessments}

A standard OGTT is performed every year, according to the guidelines described by the WHO [15]. Venous blood samples are immediately centrifuged and plasma is frozen at $-80{ }^{\circ} \mathrm{C}$ until analysis. Plasma glucose and FFA concentrations are measured using a standard enzymatic techni- ques (Glucose HK 125, ABX diagnostics, Montpellier, France; FFA-C test kit, Wako Chemicals, Neuss, Germany, respectively). Plasma insulin concentration is measured with an ELISA assay (Mercodia, Uppsala, Sweden) which shows no cross-reactivity with pro-insulin. Glycated haemoglobin $\left(\mathrm{HbA}_{1 \mathrm{c}}\right)$ is determined with the HPLC technique (reference value for our laboratory 4.4-6.2\%). Insulin sensitivity is estimated with the HOMA-index and insulin secretion with the insulinogenic index 30' (Insulin30-Insulin0)/(glucose 30-glucose0) [19]. Blood lipids are measured with standard enzymatic techniques in fasting serum samples (triglycerides: Sigma, St. Louis, USA; cholesterol: cholesterol 100, ABX diagnostics; HDL: HDL-C Roche, Indianapolis, USA). 
LDL cholesterol is calculated according to the formula of Friedewald [20].

\subsubsection{Anthropometry}

Body weight is measured on an electronical scale. BMI is calculated as the ratio of weight and height squared $\left(\mathrm{kg} / \mathrm{m}^{2}\right)$. Skinfold measurements are performed to calculate fat mass, fat free mass and body fat percentage [21]. Waist circumference (waist) is measured at the level midway between the lowest rib and the iliacal crest. Hip circumference is measured as the maximum circumference over the buttocks. Sagittal and transverse abdominal diameter are measured with the subject in a recumbent position, at the level of the iliacal crest using a sliding beam calliper.

\subsubsection{Maximal aerobic capacity}

To evaluate changes in aerobic fitness, an incremental exhaustive exercise test is performed on an electronically braked bicycle ergometer (Lode Excalibur, Groningen, Netherlands). The test starts at a workload of $0.75 \mathrm{~W} / \mathrm{kg}$ FFM for 3 min, followed by $3 \mathrm{~min}$ at $1.5 \mathrm{~W} / \mathrm{kg}$ FFM. Subsequently, workload is increased every $3 \mathrm{~min}$ by $0.5 \mathrm{~W} / \mathrm{kg}$ FFM until exhaustion. $\mathrm{O}_{2}$ consumption and $\mathrm{CO}_{2}$ production are measured with an Oxycon-Beta (Mijnhardt, Breda, Netherlands) to define maximal peak $\mathrm{VO}_{2}$.

\subsubsection{Other measurements}

At every (annual) visit a physical examination is performed, including recording a 12-lead resting ECG. Blood pressure is measured twice on the right arm with a standard sphygmomanometer, after at least 10 min of rest. Subjects taking any blood pressure-lowering medication are asked not to take these on the morning of the measurements. A 3 days food record ( 2 weekdays and 1 weekend day) is kept at the start of the study and every year thereafter. Food records are checked by a dietician and intake of nutrients is calculated with a computer program according to the Dutch food table.

\subsubsection{Outcome}

Primary outcome measure is the change in glucose tolerance (i.e. 2-h plasma glucose), one of the most important risk factors for progression to diabetes [4]. Secondary outcome measures are changes in fasting plasma glucose concentration, plasma insulin concentration, insulin resistance, $\mathrm{HbA}_{1 \mathrm{c}}$, and changes in body weight, body composition and $\mathrm{VO}_{2} \max$. Furthermore changes in cardiovascular risk factors are assessed (blood pressure and blood lipid profile).

\subsection{Statistical analysis}

Data from the intervention study are analysed according to the intention-to-treat principle. Differences between groups (over time) are analysed by unpaired $t$-tests or ANOVA (repeated measures). The level of significance is set at 0.05 .

Results of the preliminary screening were analysed with ANOVA (differences between categories) and $\chi^{2}$-testing (frequency distribution of disturbances in glucose homeostasis).

\section{Results}

In total 6108 subjects were invited to participate in the preliminary screening. Of those, 2820 subjects were willing to participate in this first OGTT. Non-response was observed in 3288 cases $(53.8 \%)$. Mean age of the non-responders was $55.7 \pm 0.1$ years, which was significantly lower than the responders $(n=2820$; age $56.8 \pm 0.1 ; P$ value $<0.001)$. No difference was seen in gender between responders and non-responders (50.6 male vs. $50.9 \%$ male, respectively, $P=\mathrm{ns}$ ). After considering the selection criteria, 379 men and women were invited for the second OGTT, of whom 177 were willing to participate. Finally, 114 subjects, 64 men and 50 women, were included in the lifestyle intervention study (SLIM).

From the 2820 subjects participating in the screening OGTT, 105 were excluded from the analysis: 48 because of recently diagnosed diabetes; 57 because of non-Caucasian ethnicity, nonfasting state, or incomplete data. Results from the remaining 2715 subjects are depicted in Table 3. WHO criteria of 1999 for capillary plasma were applied, as the glucometer Elite measures glucose levels equivalent to capillary plasma [15]. Abnor- 
Table 3

Results of the screening OGTT

\begin{tabular}{lllllll}
\hline & & NGT & IFG & IGT & Type 2 DM & $P$-value \\
\hline Number & $\%(n)$ & $69.9(1889)$ & $7.9(215)$ & $14.2(385)$ & $8.3(226)$ & $<0.0001$ \\
Sex & $(\%$ Male $)$ & 47.5 & 61.2 & 49.1 & 67.8 & $<0.0001$ \\
Age & $($ Year $)$ & $55.9 \pm 0.2$ & $58.8 \pm 0.4$ & $57.1 \pm 0.5$ & $59.8 \pm 0.4$ & $<0.0001$ \\
BMI & $\left(\mathrm{kg} / \mathrm{m}^{2}\right)$ & $28.0 \pm 0.1$ & $29.7 \pm 0.3$ & $29.5 \pm 0.2$ & $30.6 \pm 0.3$ & $<0.0001$ \\
FBG & $(\mathrm{mmol} / \mathrm{l})$ & $5.2 \pm 0.1$ & $6.3 \pm 0.1$ & $5.8 \pm 0.1$ & $7.4 \pm 0.1$ & $<0.0001$ \\
2 h BG & $(\mathrm{mmol} / \mathrm{l})$ & $6.5 \pm 0.1$ & $6.8 \pm 0.1$ & $10.1 \pm 0.1$ & $13.0 \pm 0.2^{\mathrm{a}}$ & \\
\hline
\end{tabular}

Data are mean \pm S.E.M.; $n=2715$. FBG, fasting blood glucose; 2 h BG, 2-h blood glucose; comparison of frequencies was done by $\chi^{2}$-test.

a Subjects with fasting glucose $>8.5 \mathrm{mmol} / \mathrm{l}$ did not undergo an OGTT $(n=28)$.

mal glucose homeostasis was detected in 826 subjects (30.4\%): 226 subjects with type 2 Diabetes (type 2DM, 8.3\%), 215 with impaired fasting glucose (IFG, 7.9\%) and 385 with impaired glucose tolerance (IGT, 14.2\%). Of the latter group, almost two-thirds $(n=244)$ had normal fasting glucose (NFG/IGT) and one-third $(n=$ 141) impaired fasting glucose (IFG/IGT). The prevalence of type $2 \mathrm{DM}$ and IFG was higher among men than women. A strong upward trend for age and BMI was seen from NGT to type 2 DM, with IGT and IFG in between (Table 3).

In Table 4 the prevalence of NGT, IFG, IGT and type $2 \mathrm{DM}$ is given for age and BMI groups, for men and women separately. In both men and women, prevalence of disturbed glucose homeostasis increased with age, except for IFG which reached the highest prevalence in the age group of $55-59$ years. In the population of 65 years and older, only $55.5 \%$ of the men and $63.5 \%$ of the

Table 4

Prevalence of type 2 diabetes, IGT, IFG and NGT in the screening population

\begin{tabular}{|c|c|c|c|c|c|c|c|c|c|c|}
\hline & \multicolumn{5}{|l|}{ Men } & \multicolumn{5}{|c|}{ Women } \\
\hline & $n$ & DM (\%) & IGT (\%) & IFG (\%) & NGT $(\%)$ & $n$ & DM $(\%)$ & IGT $(\%)$ & IFG (\%) & NGT $(\%)$ \\
\hline \multicolumn{11}{|c|}{ Age (years) } \\
\hline$<50$ & 289 & 6.6 & 8.0 & 6.2 & 79.2 & 254 & 0.8 & 9.1 & 2.4 & 87.8 \\
\hline $50-54$ & 256 & 7.8 & 10.2 & 13.7 & 68.4 & 252 & 2.4 & 13.9 & 6.7 & 77.0 \\
\hline $55-59$ & 289 & 11.1 & 14.5 & 12.5 & 61.9 & 281 & 6.8 & 14.6 & 7.8 & 70.8 \\
\hline $60-64$ & 301 & 14.0 & 16.3 & 9.0 & 60.8 & 322 & 8.6 & 15.8 & 6.8 & 70.5 \\
\hline$\geq 65$ & 238 & 16.8 & 20.6 & 7.1 & 55.5 & 233 & 10.3 & 19.7 & 6.4 & 63.5 \\
\hline \multicolumn{11}{|c|}{$B M I\left(\mathrm{~kg} / \mathrm{m}^{2}\right)$} \\
\hline$<27$ & 477 & 6.7 & 10.5 & 6.1 & 76.7 & 515 & 3.1 & 10.1 & 4.1 & 82.7 \\
\hline $27-30$ & 484 & 8.9 & 10.5 & 9.7 & 70.9 & 415 & 4.1 & 15.7 & 5.5 & 74.7 \\
\hline$\geq 30$ & 412 & 18.9 & 21.4 & 13.8 & 45.9 & 412 & 9.7 & 19.2 & 9.2 & 61.9 \\
\hline Total & 1373 & 11.1 & 13.8 & 9.7 & 65.4 & 1342 & $5.4^{* *}$ & 14.6 & $6.1^{* *}$ & $73.8^{* *}$ \\
\hline
\end{tabular}

**, $P<0.001$ between sexes $\left(\chi^{2}\right.$-test $)$. 
women had normal glucose homeostasis. In men and women with a BMI above $30 \mathrm{~kg} / \mathrm{m}^{2}$, diabetes was three times more prevalent and IFG and IGT were two times more prevalent, compared with those with a BMI below $27 \mathrm{~kg} / \mathrm{m}^{2}$. The prevalence of newly diagnosed diabetes was almost two times higher in men than in women in each BMI and age group. Likewise, IFG was 1.5 times more frequent in men than in women, especially in the age groups below 55 years. Additionally, more women were normoglycaemic than men $(P<0.001)$.

\section{Discussion}

\subsection{Lifestyle-intervention}

The justification of lifestyle-intervention studies is that they may prevent or postpone the onset of type 2 diabetes and related complications. Both the Finnish DPS and the US DPP reported that changing dietary and physical activity habits reduce the incidence of diabetes by about 58\% $[11,12]$. Confirmation of these results in different populations is important. SLIM will consider this in a middle-aged Dutch population at increased risk for diabetes. The Dutch population has a low prevalence of obesity [22], and Dutch subjects are known for their relatively high level of physical activity. In 1997 slightly more than one-half of the population was, on average, moderately active for more than half an hour per day [23], compared with about one-third of US adults [24]. As obesity and physical activity are important factors associated with diabetes, it is important to know whether lifestyle changes result in a comparable risk reduction in the Dutch population as in the Finnish and American population.

Dietary and physical activity intervention strategies are combined, as earlier reports indicated that the combination is most effective $[25,26]$. The intervention strategy in this randomised study is based on general public health recommendations for nutritional intake and physical activity. A regimen, based on general recommendations, is much more suitable to prevent diabetes, as it is less time consuming and much better tolerated than very intensive intervention programmes. Further- more, we will perform additional measurements in small subgroups of the intervention and control population ( $n=10$ per group) using stable isotopes, indirect calorimetry and muscle biopsies. Since type 2 diabetes and IGT are characterised by disturbances in skeletal muscle fatty acid uptake and oxidation [27-29], the question will be addressed whether changes in glucose tolerance are accompanied by changes in skeletal muscle fatty acid metabolism. These additional measurements could identify some of the mechanisms underlying the development of insulin resistance and type 2 diabetes mellitus.

\subsection{Methodological considerations}

Participation rate was relatively low in the present study, approximately $50 \%$. As subjects were selected from an ongoing monitoring project for health and disease, some 'research-fatigue' could not be excluded, and this could have led to some selection bias. Classification of the subjects was based on a single OGTT (with the glucometer Elite), and was not confirmed by repeated testing as recommended. Some misclassification might have occurred because of the known high intraindividual variability in glucose levels. However, a previous Dutch study showed that the prevalence of IGT and diabetes was not different between the first and the second test [30]. Only when the diagnosis was based on meeting classification criteria at both OGTT's, did the prevalence decrease. Finally, we tested the consistency in classification between measurements made with the glucometer Elite and measurements made with a standard enzymatic technique in venous plasma. Consistency in classification according to the WHO criteria was good $(69 \%$, kappa $0.55, P$ value $<0.001 ; n=245$; [31]).

\subsection{Preliminary screening}

The results of the preliminary screening confirm the high-risk profile of the population under study. Three out of every ten subjects had disturbed glucose homeostasis, which is quite comparable with the results reported in the STOP-NIDDM trial, which also screened in a high-risk population 
[32]. The prevalence of IGT and newly diagnosed diabetes in the screening population was higher than reported in the Dutch Hoorn Study over the period $1989-1992(10.3 \%$ for IGT and $4.8 \%$ for newly diagnosed diabetes [33]). This may reflect the world-wide increasing prevalence of disturbances in glucose homeostasis [1], and parallels the increasing prevalence of obesity reported in the Dutch population [22]. However, in the Hoorn study the old WHO-criteria (1985) were used. Since the fasting glucose level for the diagnosis of diabetes has now been reduced, this could partly explain the higher prevalence of diabetes in our study, but not the higher prevalence of IGT.

In line with other populations, the present study confirmed that IGT is considerably more prevalent than IFG, and that overlap between the two categories is limited [3]. This limited overlap points towards the difference in metabolic background: IGT is primarily associated with insulin resistance while IFG is associated with a more pronounced defect in insulin secretion and endogenous glucose output [34].

A strong positive relation was observed between increasing age and prevalence of IGT and diabetes. For IFG, the highest prevalence was seen in middle-aged subjects (aged 55-59 years). This is a consistent finding in European populations, particularly among men [3]. The prevalence of disturbances in glucose homeostasis was almost 2-fold higher in the group with a BMI $>30 \mathrm{~kg} / \mathrm{m}^{2}$ compared with those with a BMI $<30 \mathrm{~kg} / \mathrm{m}^{2}$. This underscores earlier reports, showing dramatic increases in the relative risk of diabetes in the highest BMI groups, compared with the lowest BMI group [35].

Type 2 diabetes is generally more prevalent in women compared with men [1]. In contrast, we observed a prevalence of diabetes being two times higher in males than in females, in all BMI and age groups. In the Finnmark study [36], BMI was reported to be a dominant risk factor for both sexes. In women, however, the relationship was confounded by other factors such as blood pressure, height, HDL, glucose, smoking and physical activity. Furthermore, in addition to over-all adiposity, body fat distribution is an important risk factor for diabetes [35]. Thus, differences in other risk factors, beside age and BMI, can underlie the observed higher prevalence of diabetes in men in the present study.

\subsection{Conclusion}

The high prevalence of disturbances in glucose homeostasis observed in the preliminary screening underscores the importance of early interventions in those at risk for developing diabetes. Changes in dietary habits and physical activity have shown to reduce the incidence of diabetes. Additional studies are required to confirm these results in different populations with a different dietary and physical activity background. SLIM will address this question in the Dutch population.

\section{Acknowledgements}

We are grateful to Rob van Dam, Tanja Hermans-Limpens, and Ilse Nijs for their work during the preliminary screening. This study is supported by grants from the Netherlands Organisation for Scientific Research (ZonMW: 940-35-034) and the Dutch Diabetes Research Foundation (DFN: 98.901).

\section{References}

[1] H. King, R.E. Aubert, W.H. Herman, Global burden of diabetes, 1995-2025: prevalence, numerical estimates, and projections, Diabetes Care 21 (1995) 1414-1431.

[2] P. Zimmet, K.G. Alberti, J. Shaw, Global and societal implications of the diabetes epidemic, Nature 414 (2001) $782-787$.

[3] N. Unwin, J. Shaw, P. Zimmet, K.G. Alberti, Impaired glucose tolerance and impaired fasting glycaemia: the current status on definition and intervention, Diabetic Med. 19 (2002) 708-723.

[4] S.L. Edelstein, W.C. Knowler, R.P. Bain, et al., Predictors of progression from impaired glucose tolerance to NIDDM: an analysis of six prospective studies, Diabetes 46 (1997) 701-710.

[5] F. de Vegt, J.M. Dekker, A. Jager, et al., Relation of impaired fasting and postload glucose with incident type 2 diabetes in a Dutch population: the Hoorn Study, J. Am. Med. Assoc. 285 (2001) 2109-2113.

[6] J.A. Marshall, S. Hoag, S. Shetterly, R.F. Hamman, Dietary fat predicts conversion from impaired glucose 
tolerance to NIDDM. The San Luis Valley Diabetes Study, Diabetes Care 17 (1994) 50-56.

[7] K.F. Eriksson, F. Lindgarde, Prevention of type 2 (noninsulin-dependent) diabetes mellitus by diet and physical exercise. The 6-year Malmo feasibility study, Diabetologia 34 (1991) 891-898.

[8] R.C. Page, K.E. Harnden, J.T. Cook, R.C. Turner, Can life-styles of subjects with impaired glucose tolerance be changed? A feasibility study, Diabetic Med. 9 (1992) 562 566 .

[9] D.M. Bourn, J.I. Mann, B.J. McSkimming, M.A. Waldron, J.D. Wishart, Impaired glucose tolerance and NIDDM: does a lifestyle intervention program have an effect, Diabetes Care 17 (1994) 1311-1319.

[10] X.R. Pan, G.W. Li, Y.H. Hu, et al., Effects of diet and exercise in preventing NIDDM in people with impaired glucose tolerance. The Da Qing IGT and Diabetes Study, Diabetes Care 20 (1997) 537-544.

[11] J. Tuomilehto, J. Lindstrom, J.G. Eriksson, et al., Prevention of type 2 diabetes mellitus by changes in lifestyle among subjects with impaired glucose tolerance, New Engl. J. Med. 344 (2001) 1343-1350.

[12] W.C. Knowler, E. Barrett-Connor, S.E. Fowler, et al., Reduction in the incidence of type 2 diabetes with lifestyle intervention or metformin, New Engl. J. Med. 346 (2002) $393-403$.

[13] J.L. Chiasson, R.G. Josse, R. Gomis, M. Hanefeld, A. Karasik, M. Laakso, Acarbose for prevention of type 2 diabetes mellitus: the STOP-NIDDM randomised trial, Lancet 359 (2002) 2072-2077.

[14] R.M. van Dam, J.M. Boer, E.J. Feskens, J.C. Seidell, Parental history of diabetes modifies the association between abdominal adiposity and hyperglycemia, Diabetes Care 24 (2001) 1454-1459.

[15] World Health Organization, Definition, diagnosis and classification of diabetes mellitus, Report of a WHO Consultation. Part 1: Diagnosis and Classification of Diabetes Mellitus, Geneva, Switzerland, 1999, Publication WHO/NCD/NCS/99.2.

[16] J. Eriksson, J. Lindstrom, T. Valle, et al., Prevention of Type II diabetes in subjects with impaired glucose tolerance: the Diabetes Prevention Study (DPS) in Finland. Study design and 1-year interim report on the feasibility of the lifestyle intervention programme, Diabetologia 42 (1999) 793-801.

[17] American College of Sports Medicine Position Stand, The recommended quantity and quality of exercise for developing and maintaining cardiorespiratory and muscular fitness, and flexibility in healthy adults, Med. Sci. Sports Exerc. 30 (1998) 975-991.

[18] J. Eriksson, J. Tuominen, T. Valle, et al., Aerobic endurance exercise or circuit-type resistance training for individuals with impaired glucose tolerance, Horm. Metab. Res. 30 (1998) 37-41.

[19] M. Albareda, J. Rodriguez-Espinosa, M. Murugo, A. de Leiva, R. Corcoy, Assessment of insulin sensitivity and beta-cell function from measurements in the fasting state and during an oral glucose tolerance test, Diabetologia 43 (2000) 1507-1511.

[20] W.T. Friedewald, R.I. Levy, D.S. Fredrickson, Estimation of the concentration of low-density lipoprotein cholesterol in plasma, without use of the preparative ultracentrifuge, Clin. Chem. 18 (1972) 499-502.

[21] J.V. Durnin, J. Womersley, Body fat assessed from total body density and its estimation from skinfold thickness: measurements on 481 men and women aged from 16 to 72 years, Br. J. Nutr. 32 (1974) 77-97.

[22] T.L. Visscher, D. Kromhout, J.C. Seidell, Long-term and recent time trends in the prevalence of obesity among Dutch men and women, Int. J. Obes. Relat. Metab. Disord. 26 (2002) 1218-1224.

[23] A.J. Schuit, E.J. Feskens, J.C. Seidell, Physical activity in relation to sociodemographic variables and health status of adult men and women in Amsterdam, Doetinchem and Maastricht, Ned Tijdschr Geneeskd 143 (1999) 1559-1564 (Dutch).

[24] D.A. Jones, B.E. Ainsworth, J.B. Croft, C.A. Macera, E.E. Lloyd, H.R. Yusuf, Moderate leisure-time physical activity: who is meeting the public health recommendations? A national cross-sectional study, Arch. Fam. Med. 7 (1998) 285-289.

[25] P.A. Torjesen, K.I. Birkeland, S.A. Anderssen, I. Hjermann, I. Holme, P. Urdal, Lifestyle changes may reverse development of the insulin resistance syndrome. The Oslo Diet and Exercise Study: a randomized trial, Diabetes Care 20 (1997) 26-31.

[26] G. Li, Y. Hu, W. Yang, et al., Effects of insulin resistance and insulin secretion on the efficacy of interventions to retard development of type 2 diabetes mellitus: the DA Qing IGT and Diabetes Study, Diabetes Res. Clin. Pract. 58 (2002) 193-200.

[27] D.E. Kelley, J.A. Simoneau, Impaired free fatty acid utilization by skeletal muscle in non-insulin-dependent diabetes mellitus, J. Clin. Invest. 94 (1994) 2349-2356.

[28] E.E. Blaak, A.J. Wagenmakers, J.F. Glatz, et al., Plasma FFA utilization and fatty acid-binding protein content are diminished in type 2 diabetic muscle, Am. J. Physiol. Endocrinol. Metab. 279 (2000) E146-E154.

[29] M. Mensink, E.E. Blaak, M.A. van Baak, A.J. Wagenmakers, W.H. Saris, Plasma free fatty acid uptake and oxidation are already diminished in subjects at high risk for developing type 2 diabetes, Diabetes 50 (2001) 2548 2554.

[30] J.M. Mooy, P.A. Grootenhuis, H. de Vries, et al., Intraindividual variation of glucose, specific insulin and proinsulin concentrations measured by two oral glucose tolerance tests in a general Caucasian population: the Hoorn Study, Diabetologia 39 (1996) 298-305.

[31] M. Kruijshoop, E.J.M. Feskens, E.E. Blaak, R.J. Heine, T.W.A. de Bruin, Validation of capillary glucose measurements to detect type 2 diabetes mellitus in the general population: the CoDAM-study, Diabetologia 42 (2002) A98 (abstract). 
[32] J.L. Chiasson, R. Gomis, M. Hanefeld, R.G. Josse, A. Karasik, M. Laakso, The STOP-NIDDM Trial: an international study on the efficacy of an alpha-glucosidase inhibitor to prevent type 2 diabetes in a population with impaired glucose tolerance: rationale, design, and preliminary screening data. Study to prevent non-insulindependent diabetes mellitus, Diabetes Care 21 (1998) $1720-1725$.

[33] J.M. Mooy, P.A. Grootenhuis, H. de Vries, et al., Prevalence and determinants of glucose intolerance in a Dutch caucasian population. The Hoorn Study, Diabetes Care 18 (1995) 1270-1273.
[34] C. Weyer, C. Bogardus, R.E. Pratley, Metabolic characteristics of individuals with impaired fasting glucose and/or impaired glucose tolerance, Diabetes 48 (1999) 2197-2203.

[35] J.M. Chan, E.B. Rimm, G.A. Colditz, M.J. Stampfer, W.C. Willett, Obesity, fat distribution, and weight gain as risk factors for clinical diabetes in men, Diabetes Care 17 (1994) 961-969.

[36] I. Njolstad, E. Arnesen, P.G. Lund-Larsen, Sex differences in risk factors for clinical diabetes mellitus in a general population: a 12-year follow-up of the Finnmark Study, Am. J. Epidemiol. 147 (1998) 49-58. 